J. Lake Sci.(湖泊科学), 2016, 28(2): 387-394

DOI 10. 18307/2016. 0219

(c) 2016 by Journal of Lake Sciences

\title{
呼伦湖鱼类群落结构及其渔业资源变化
}

\author{
毛志刚,谷孝鸿"**曾庆飞 \\ ( 中国科学院南京地理与湖泊研究所湖泊与环境国家重点实验室,南京 210008)
}

\begin{abstract}
摘 要: 根据 2014-2015 年在呼伦湖进行的鱼类资源拖网调查,结合历年渔业捕捞资料,分析该水域的鱼类群落结构及 渔业资源发展趋势. 结果表明: 本次调查共采获鱼类 21 种, 隶属 4 目 6 科 21 属, 其中鲤形目种类最多, 占总数的 $81.0 \%$; 群落优势种为贝氏频(Hemiculter bleekeri)、红鯺原鲌(Cultrichthys erythropterus)、鲤(Cyprinus carpio)、银鲫( Carassius auratus gibelio) 和瓦氏雅罗鱼 (Leuciscus waleckii), 鱼类群落的丰富度指数、Shannon-Wiener 多样性指数和均匀度指数均偏低. 东 部、西部湖区间的鱼类群落组成存在一定差异, 其中西部湖区的鱼类物种数量较少, 但大中型鱼类比例及生物多样性较 高. 与历史资料相比, 呼伦湖鱼类的物种数量下降, 优势种组成发生较大变化, 鱼类个体小型化趋势明显, 而捕捞强度过 大、湖泊富营养化加剧及气候水文条件变化是导致呼伦湖渔业资源衰退的主要因素.
\end{abstract}

关键词: 鱼类种类组成;生态类型;优势种;生物多样性;渔业资源小型化;呼伦湖

\section{The structure of fish community and changes of fishery resources in Lake Hulun}

\section{MAO Zhigang, GU Xiaohong *** \&ENG Qingfei}

( State Key Laboratory of Lake Science and Environment, Nanjing Institute of Geography and Limnology, Chinese Academy of Sciences, Nanjing 210008, P.R.China)

\begin{abstract}
Based on the historical data of fish catches and bottom trawl surveys on fish assemblage from 2014 to 2015 in Lake Hulun, the characteristics of fish community structure and dynamic variation of fishery resources were analyzed. The results showed that only 21 species ( belonging to 21 genera, 6 families and 4 orders) were collected in Lake Hulun and Cypriniformes had the largest species number, accounting for $81.0 \%$ of the total species captured. The dominant species were Hemiculter bleekeri, Cultrichthys erythropterus, Cyprinus carpio, Carassius auratus gibelio and Leuciscus waleckii, and the Margalef richness index, ShannonWiener index and Pielou evenness index were low in Lake Hulun. In addition, the percentage of large fishes and the diversity indexes were found higher in the western lake region than those in the eastern lake region, whereas the number of fish species showed the reverse trend. Compared with historical data, we found that the composition of fish species and the dominant species had changed and the miniaturized tendency of fish resources was more obvious. Overfishing, lake eutrophication and changes of climatic and hydrological conditions are potential underlying reasons for observed shifts in the fish assemblage.
\end{abstract}

Keywords: Composition of fish species; ecological guilds; dominant species; biodiversity; miniaturization of fish resources; Lake Hulun

呼伦湖, 也称达妻湖, 为中国第四大淡水湖, 位于内蒙古呼伦贝尔盟西部高原境内. 呼伦湖湖泊面积 $2343 \mathrm{~km}^{2}$, 平均水深 $5.7 \mathrm{~m}$, 总储水量 $138.5 \times 10^{8} \mathrm{~m}^{3[1]}$. 呼伦湖作为中国北方第一大湖, 与其周围湿地及径流 构成的淡水资源, 在维持生态系统平衡和保护生物多样性方面发挥着巨大作用的同时,也为其流域内生活 的居民提供了重要的渔业资源 ${ }^{[2]}$. 但自 1980s 以来, 随着呼伦湖流域面源污染物的不断输人, 湖泊水体质量 持续下降, 蓝藻水华频发 ${ }^{[1]}$, 同时由于过度捕捞以及水位下降等气候条件变化影响 ${ }^{[3]}$, 呼伦湖的优质渔业资

* 国家科技支撑计划项目 (2015BAD13B06)、江苏省水产三新工程项目 (Y2014-39) 和湖泊与环境国家重点实验室开 放基金项目(2014SKL017)联合资助. 2015-04-19 收稿; 2015-06-08 收修改稿. 毛志刚 (1984 ), 男, 博士; E-mail: zgmao@ niglas. ac.cn.

** 通信作者; E-mail: xhgu@ niglas.ac.cn. 
源不断减少,鱼类群落结构和生物多样性特征发生重大变化,影响呼伦湖渔业的可持续发展.

呼伦湖的鱼类调查最早由内蒙古自治区与呼伦贝尔盟于 1950s 进行, 其后内蒙古自治区渔业区划办公 室组织调查组, 在 1981-1982 年间对呼伦湖的渔业资源进行 1 次详细的综合调查 ${ }^{[4]}$. 这些调查的内容主要 集中在鱼类资源组成、鱼类种属的记录、鱼类区系的演化以及生物学特性的研究等 ${ }^{[5]}$. 近年来,一些学者在 呼伦湖几种主要鱼类的食性、繁殖生物学、营养成分等方面开展研究 ${ }^{[6-8]}$, 但关于呼伦湖渔业资源的演变趋 势及其影响因素的探讨较少 ${ }^{[9]}$, 特别是呼伦湖鱼类群落结构和多样性特征的研究还未见报道. 因此, 本研 究拟在对呼伦湖历年渔获物资料收集整理的基础上,结合 2014-2015 年进行的冰下拖网调查, 分析呼伦湖 鱼类群落结构和多样性的空间分布特征, 并探讨渔业资源的发展趋势及其制约因素, 以期为呼伦湖鱼类资 源的恢复和可持续发展提供科学依据.

\section{1 材料与方法}

\section{1 调查方法}

2014 年 12 月至 2015 年 1 月, 在呼伦湖共设置调查点位 12 个 (图 1), 采用机引冰下大拉网 (网长 800 $\mathrm{m}$, 网目 $3 \sim 8 \mathrm{~cm}$ ) 进行水平拖网调查; 同时, 在全湖范围内收集渔民渔获物以增加物种数. 采集的鱼类标本 现场鉴定种类,进行体长、体重等生物学测量,并记录数量、采集地等相关数据. 采集到的鱼类用 $10 \%$ 甲醛 溶液固定,鱼类鉴定参考文献[10-11]进行.

呼伦湖不同湖区间环境特征差别明显, 为对呼伦湖鱼类群落结构及其生物多样性的空间分布特征进行 比较, 将呼伦湖划分为东部和西部 2 个湖区. 其中东部湖岸较低, 部分地区已沼泽化, 且有挺水与沉水植物 分布, 湖底多为细砂砾层; 西部湖岸陡峭, 湖区较深, 湖底多为泥质土层 (图 1). 乌尔逊河和克鲁伦河分别从 呼伦湖东部和南部汇人.

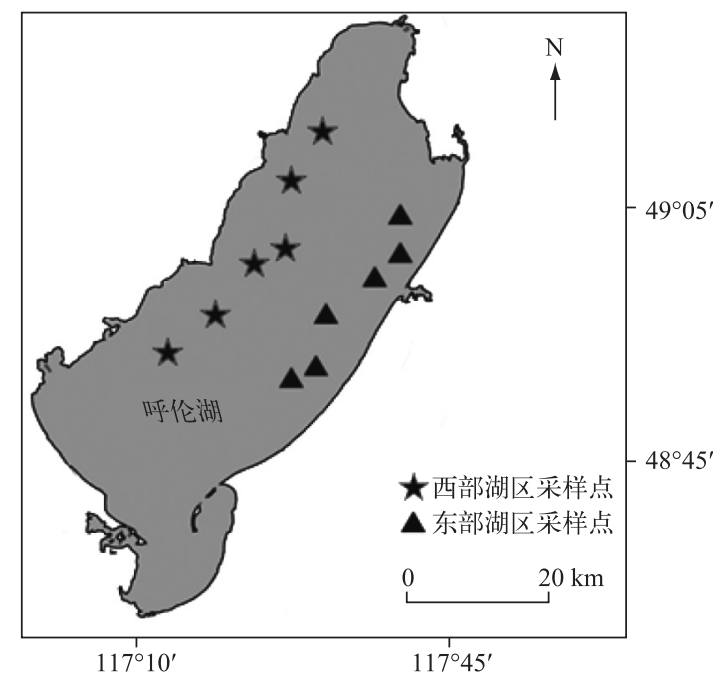

图 1 呼伦湖鱼类调查点位分布

Fig. 1 Distribution of sampling sites in Lake Hulun

\section{2 数据分析}

呼伦湖 1949-2014 年的渔业捕捞产量数据由呼伦湖渔业有限公司提供, 渔获物种类及产量均为各捕捞 队的生产统计, 渔具主要为冰下大拉网和明水大拉网.

本文鱼类群落多样性的分析运用 Margalef 物种丰富度指数 $(D)$ 、Shannon-Wiener 多样性指数 $\left(H^{\prime}\right)$ 和 Pielou 均匀度指数 $\left(J^{\prime}\right)^{[12]}$, 公式分别为:

$$
\begin{aligned}
D & =(S-1) / \ln N \\
H^{\prime} & =-\sum_{i=1}^{S} P_{i} \cdot \ln P_{i}
\end{aligned}
$$




$$
J^{\prime}=H^{\prime} / \ln S
$$

式中, $S$ 为种类数; $N$ 为总尾数; $P$ 为第 $i$ 种鱼所占的比例.

Pinkas 的相对重要性指数 $(I R I)$ 被用来研究鱼类群落优势种的成分 ${ }^{[13]}$,其计算公式为:

$$
I R I=(N \%+W \%) F \%
$$

式中, $N \%$ 为某一种类的尾数占总尾数的百分比; $W \%$ 为某一种类的质量占总质量的百分比; $F \%$ 为某一种类 出现的站数占调查总站数的百分比. 本文选取 IRI 值大于 100 的物种为优势种.

全部数据的统计分析用 SPSS 19.0 软件完成.

\section{2 结果与分析}

\section{1 鱼类种类及区系组成}

本次调查在呼伦湖地区共采集到鱼类 21 种,隶属 4 目 6 科 21 属(表 1). 其中鲤形目 (17 种)种类最多, 占调查物种总数的 $81.0 \%$; 其次是鮏形目 ( 2 种), 其他 2 目各 1 种. 在科的水平上,鲤科 ( 15 种) 种类最多, 占总数的 $71.4 \%$; 鱾科 2 种, 其它 4 科各 1 种. 呼伦湖东部湖区、西部湖区分别采集到鱼类 20 和 14 种(表 $1)$,且各湖区均以鲤形目鱼类为主,分别占总数的 $80.0 \% \sim 85.7 \%$,其他目的种类数较少.

呼伦湖鱼类按其起源分布和生态特征可分为 5 个区系复合体: 红鳛原鲌、贝氏餐及引入的鲢、鳙等属于 中国平原区系复合体 (9 种, 42. 9\%) ; 黑斑狗鱼、瓦氏雅罗鱼、银鲫等属于北方平原区系复合体 ( 5 种, $23.8 \%$ ); 鲤、鲇等属于晚第三纪早期区系复合体 ( 5 种, $23.8 \%$ ); 哲罗鮏和江鮽分别属于北方山地区系复合 体和北极淡水区系复合体 (各 1 种, $4.8 \%$ )。呼伦湖鱼类种类虽较少, 但区系组成却较为复杂,其中北方平原 区系、北方山地区系和北极淡水区系的鱼类 (共 7 种), 体现了北方区的鱼类区系组成特征.

\section{2 鱼类生态类型}

呼伦湖鱼类按其栖息环境和洄游方式可分为 3 种生态类型 (表 1). 冷水溪流性鱼类: 共有哲罗鲭和江 鳕 2 种, 占呼伦湖鱼类物种总数的 $9.5 \%$; 江湖半洄游性鱼类: 共有鲢、鳙 2 种, 占总数的 $9.5 \%$, 但这些鱼类 主要为人工增殖放流的移人种; 湖泊定居性鱼类: 共有 17 种鱼类,占总数的 $81.0 \%$, 这些鱼均能在湖区水域 内繁殖后代,在呼伦湖及其附属水体中占绝对优势.

按食性类型可将呼伦湖鱼类划分为鱼食性、杂食性、底栖生物食性和浮游生物食性 4 类 (表 1). 黑斑狗 鱼、红鯺原鲌等凶猛鱼类以鱼、虾为主要食物, 为典型的鱼食性鱼类, 占总数的 $33.3 \%$; 鲤、银鲫等鱼类对动 植物食物都能吞食, 为杂食性鱼类, 占总数的 $33.3 \%$; 唇鳃、蛇鮈等则以栖息于湖底表面或沉积物中的生物 为食, 为底栖食性鱼类, 占 $19.0 \%$; 贝 氏餐等浮游食性鱼类则占 $14.3 \%$. 其中呼伦湖不同湖区的鱼类生态类 型组成亦存在差异, 东部湖区鱼食性和底栖食性鱼类的种类数和比例均高于西部湖区 (表 1).

\section{3 鱼类优势种组成}

按照 IRI 值的大小对所捕获鱼类进行排序, 排在前 10 位的种类及其资源指数均列于表 2 . 全湖区域内 的优势种鱼类为贝氏粲、红鯺原鲌、鲤、银鲫和瓦氏雅罗鱼共 5 种 (IRI 值大于 100), 而这几种鱼在东部、西部 湖区的优势度存在一定差别, 其中红鯺原鲌在东部湖区优势程度明显, 而鲤在西部湖区分布优势明显. 呼 伦湖鱼类优势种中, 贝氏粲的 IRI 值最高, 明显大于其他优势种, 其质量百分比占总鱼类的 $82.5 \%$; 除了贝氏 粲和瓦氏雅罗鱼外, 优势种中的其它种类均为大中型鱼类, 但这些大中型鱼类的质量百分比总和仅为 $15.3 \%$ (表 2).

\section{4 生物多样性指数}

呼伦湖鱼类群落的物种丰富度指数 $(D)$ 、Shannon-Wiener 多样性指数 $\left(H^{\prime}\right)$ 和均匀度指数 $\left(J^{\prime}\right)$ 总体偏低 且东、西部湖区间存在差异 (图 2). 呼伦湖水域的 12 个调查样方中, $D$ 的变动幅度较大, 在 $0.67 \sim 1.75$ 之 间, 平均值为 1.21. $H^{\prime}$ 和 $J^{\prime}$ 均用生物量和个体数量 2 种方法计算, $H^{\prime}{ }_{\mathrm{N}}$ 和 $H^{\prime}{ }_{\mathrm{W}}$ 的变动范围分别为 $0.08 \sim 0.21$ 和 $0.48 \sim 1.07, J^{\prime}{ }_{\mathrm{N}}$ 和 $J^{\prime}{ }_{\mathrm{W}}$ 的变动范围分别为 $0.03 \sim 0.08$ 和 $0.16 \sim 0.36$, 其中基于个体数量的多样性指标 $H^{\prime}{ }_{\mathrm{N}}$ 和 $J^{\prime}{ }_{\mathrm{N}}$ 均小于基于生物量的多样性指标 $H^{\prime}{ }_{\mathrm{W}}$ 和 $J^{\prime}{ }_{\mathrm{W}}$. 除 $D$ 外, 不同湖区的 $H^{\prime}$ 和 $J^{\prime}$ 平均值均表现为西部湖区高 于东部湖区 (图 2). 对 2 个湖区的生物多样性指标进行单因子方差分析, 其中仅均匀度指数 $J^{\prime}{ }_{W}$ 间呈显著 性差异 $(P<0.05)$. 
表 1 呼伦湖鱼类种类组成 *

Tab. 1 Composition of fish species in Lake Hulun

\begin{tabular}{|c|c|c|c|c|}
\hline \multirow{2}{*}{ 种类 } & \multirow{2}{*}{ 生态类型 } & \multirow{2}{*}{ 历史记录种 ${ }^{[4,14]}$} & \multicolumn{2}{|c|}{$2014-2015$ 年 } \\
\hline & & & 西部湖区 & 东部湖区 \\
\hline \multicolumn{5}{|l|}{ 鲑科 Salmonidae } \\
\hline 哲罗鲑 Hucho taimen & $\mathrm{M}, \mathrm{P}$ & $\triangle$ & & + \\
\hline 细鳞鲑 Brachymystax lenok & $\mathrm{M}, \mathrm{P}$ & $\triangle$ & & \\
\hline \multicolumn{5}{|l|}{ 狗鱼科 Esocidae } \\
\hline 黑斑狗鱼 Esox reicherti & $\mathrm{S}, \mathrm{P}$ & $\triangle$ & + & + \\
\hline \multicolumn{5}{|l|}{ 银鱼科 Salangidae } \\
\hline 大银鱼 Protosalanx hyalocranius & $\mathrm{S}, \mathrm{P}$ & $\triangle$ & & \\
\hline \multicolumn{5}{|l|}{ 鲤科 Cyprinidae } \\
\hline 瓦氏雅罗鱼 Leuciscus waleckii waleckii & $\mathrm{S}, \mathrm{O}$ & $\triangle$ & + & + \\
\hline 草鱼 Ctenopharyngodon idella & S, G & $\triangle$ & & \\
\hline 拟赤梢鱼 Pseudaspius leptocephalus & $\mathrm{S}, \mathrm{P}$ & $\triangle$ & & + \\
\hline 贝氏粲 Hemiculter bleekeri & $\mathrm{S}, \mathrm{SF}$ & $\triangle$ & + & + \\
\hline 团头鲂 Megalobrama amblycephala & $S, G$ & $\triangle$ & & \\
\hline 红鯺原鲌 Cultrichthys erythropterus & $\mathrm{S}, \mathrm{P}$ & $\triangle$ & + & + \\
\hline 蒙古鲌 Culter mongolicus mongolicus & $\mathrm{S}, \mathrm{P}$ & $\triangle$ & + & + \\
\hline 细鳞鲖 Xenocypris microlepis & $S, G$ & $\triangle$ & & \\
\hline 鲢 Hypophthalmichthys molitrix & $\mathrm{M}, \mathrm{SF}$ & $\triangle$ & + & + \\
\hline 鳙 Aristichthys nobilis & $\mathrm{M}, \mathrm{SF}$ & $\triangle$ & + & + \\
\hline 唇鳃 Hemibarbus labeo & $\mathrm{S}, \mathrm{DF}$ & $\triangle$ & + & + \\
\hline 花䱻 Hemibarbus maculatus & $\mathrm{S}, \mathrm{DF}$ & $\triangle$ & & \\
\hline 犬首鮈 Gobio cynocephalus & $\mathrm{S}, \mathrm{DF}$ & $\triangle$ & & \\
\hline 细体鮈 Gobio tenuicorpus & $\mathrm{S}, \mathrm{DF}$ & $\triangle$ & & \\
\hline 兴凯领须鮈 Gnathopogon chankaensis & $\mathrm{S}, \mathrm{DF}$ & $\triangle$ & & \\
\hline 条纹似白鮈 Paraleucogobio strigatus & $\mathrm{S}, \mathrm{DF}$ & $\triangle$ & & \\
\hline 蛇鮈 Saurogobio dabryi & $\mathrm{S}, \mathrm{DF}$ & $\triangle$ & & + \\
\hline 突吻鮈 Rostrogobio amurensis & $\mathrm{S}, \mathrm{O}$ & $\triangle$ & + & \\
\hline 东北鳈 Sarcocheilichthys lacustris & $\mathrm{S}, \mathrm{O}$ & $\triangle$ & + & + \\
\hline 麦穗鱼 Pseudorasbora parva & $\mathrm{S}, \mathrm{O}$ & $\triangle$ & + & + \\
\hline 黑龙江鰟鮍 Rhodeus sericeus & $\mathrm{S}, \mathrm{O}$ & $\triangle$ & & \\
\hline 大鳍鱊 Acheilognathus macropterus & $\mathrm{S}, \mathrm{O}$ & $\triangle$ & & + \\
\hline 银鲫 Carassius auratus gibelio & $\mathrm{S}, \mathrm{O}$ & $\triangle$ & + & + \\
\hline 鲤 Cyprinus carpio & $\mathrm{S}, \mathrm{O}$ & $\triangle$ & + & + \\
\hline \multicolumn{5}{|l|}{ 鳅科 Cobitidae } \\
\hline 黑龙江泥鳅 Misgurnus mohoity & $\mathrm{S}, \mathrm{DF}$ & $\triangle$ & & + \\
\hline 黑龙江花鱾 Cobitis lutheri & $\mathrm{S}, \mathrm{DF}$ & $\triangle$ & & + \\
\hline \multicolumn{5}{|l|}{ 鲇科 Siluridae } \\
\hline 鲇 Silurus asotus & $\mathrm{S}, \mathrm{P}$ & $\triangle$ & + & + \\
\hline \multicolumn{5}{|l|}{ 鳕科 Gadidae } \\
\hline 江鳕 Lota lota & $\mathrm{M}, \mathrm{P}$ & $\triangle$ & & + \\
\hline \multicolumn{5}{|l|}{ 塘鳢科 Eleotridae } \\
\hline 葛氏鲈塘鳢 Perccottus glehni & $\mathrm{S}, \mathrm{P}$ & $\triangle$ & & \\
\hline
\end{tabular}

* M : 洄游性鱼类; $\mathrm{S}$ : 定居性鱼类; $\mathrm{P}$ :鱼食性; $\mathrm{O}$ : 杂食性; DF : 底栖食性; $\mathrm{SF}$ : 浮游食性; G : 草食性. $\triangle$ 表示文献记录种; + 表 示本次调查记录种. 
表 2 呼伦湖不同湖区的鱼类优势种组成

Tab. 3 Composition of dominant fish species in different lake regions of Lake Hulun

\begin{tabular}{|c|c|c|c|c|c|c|c|c|c|}
\hline \multirow{2}{*}{ 种类 } & \multicolumn{3}{|c|}{ 全湖 } & \multicolumn{3}{|c|}{ 东部湖区 } & \multicolumn{3}{|c|}{ 西部湖区 } \\
\hline & $N \%$ & $W \%$ & IRI & $N \%$ & $W \%$ & IRI & $N \%$ & $W \%$ & IRI \\
\hline 贝氏粲 & 98.1 & 82.5 & 18054.6 & 98.2 & 86.8 & 18502.2 & 97.9 & 78.2 & 17607. 0 \\
\hline 红鳍原鲌 & 0.8 & 5.2 & 601.9 & 0.8 & 5.3 & 605.1 & 0.8 & 5.2 & 598.7 \\
\hline 鲤 & 0.4 & 8.2 & 857.7 & 0.2 & 4. 7 & 496.8 & 0.6 & 11.6 & 1218.6 \\
\hline 银鲫 & 0.3 & 1.9 & 219.4 & 0.2 & 1.5 & 174. 2 & 0.3 & 2.3 & 264.5 \\
\hline 瓦氏雅罗鱼 & 0.4 & 0.9 & 127.7 & 0.5 & 1.0 & 146.8 & 0.4 & 0.7 & 108.6 \\
\hline 鳙 & 0.0 & 0.5 & 49.2 & 0.0 & 0.2 & 21.3 & 0.0 & 0.8 & 77. 1 \\
\hline 鲇 & 0.0 & 0.3 & 31.4 & 0.0 & 0.2 & 19.2 & 0.0 & 0.4 & 43.5 \\
\hline 黑斑狗鱼 & 0.0 & 0.2 & 23.3 & 0.0 & 0.1 & 13.8 & 0.0 & 0.3 & 32.9 \\
\hline 鲢 & 0.0 & 0.3 & 26.1 & 0.0 & 0.1 & 11.5 & 0.0 & 0.4 & 40.8 \\
\hline 东北鳈 & 0.0 & 0.0 & 1.1 & 0.0 & 0.0 & 2.1 & - & - & - \\
\hline 唇鳃 & - & - & - & - & - & - & 0.0 & 0.0 & 1.9 \\
\hline
\end{tabular}

* 表中仅列出各湖区 IRI 值在前 10 位的鱼类种类.

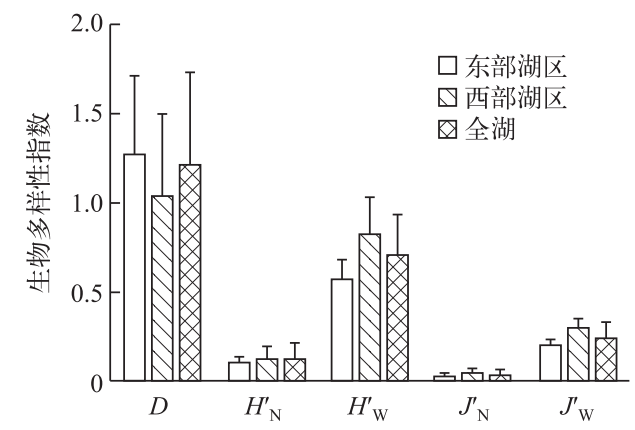

图 2 呼伦湖不同湖区的鱼类生物多样性指数

Fig.2 Diversity indexes of fish community in different lake regions of Lake Hulun

\section{5 渔业资源变化趋势}

呼伦湖历年的渔获物统计结果如图 3 所示, 1949-2014 年的 66 年间,呼伦湖鱼类捕捞产量的发展趋势 大致可分为波动、增长和下降 3 个阶段. 波动阶段: 1949-1972 年的 24 年间捕捞产量分布范围为 1917 $9193 \mathrm{t}$, 年均捕捞产量 $5073 \mathrm{t}$; 增长阶段: 1973-2002 年的 30 年间捕捞产量从 $6910 \mathrm{t}$ 逐步上升至 $15908 \mathrm{t}$, 平 均每年增长 $299.9 \mathrm{t}$, 其中 2002 年的单位水域产量达到 $67.9 \mathrm{~kg} / \mathrm{hm}^{2}$; 下降阶段: $2003-2014$ 年的 12 年间捕 捞产量迅速下降,其中 2014 年的捕捞量仅为 2002 年的 $25.5 \%$.

呼伦湖不同年份的自然渔业结构如表 3 所示 (不含白虾), 1970s、1980s 呼伦湖的渔业单位产量虽相对 较低, 但鲤、银鲫、鲌鱼等大中型鱼类的比例占 $28.7 \%$ 31. 9\%, 渔业结构相对合理 . 1990s 渔业单位水域产 量最高, 达到 $38.9 \mathrm{~kg} / \mathrm{hm}^{2}$, 但大中型优质鱼类的比例下降至 10.5\%; 而 2000-2014 年间的渔业单位水域产 量仅为 $22.5 \mathrm{~kg} / \mathrm{hm}^{2}$, 大中型鱼类比例更是下降至 $4.5 \%$. 与之相对, 图 3 和表 3 均显示呼伦湖渔获物组成 中, 小型浮游食性鱼类贝氏餐的产量有较大幅度上升, 所占比例从 1970s、1980s 的 68. 1\% 71.0\%增至目前 的 $95.4 \%$, 成为呼伦湖鱼类群落中的绝对优势种, 以贝氏粲为代表的这种状况典型地反映了呼伦湖鱼类“优 势种单一化”和“小型化”的发展方向. 


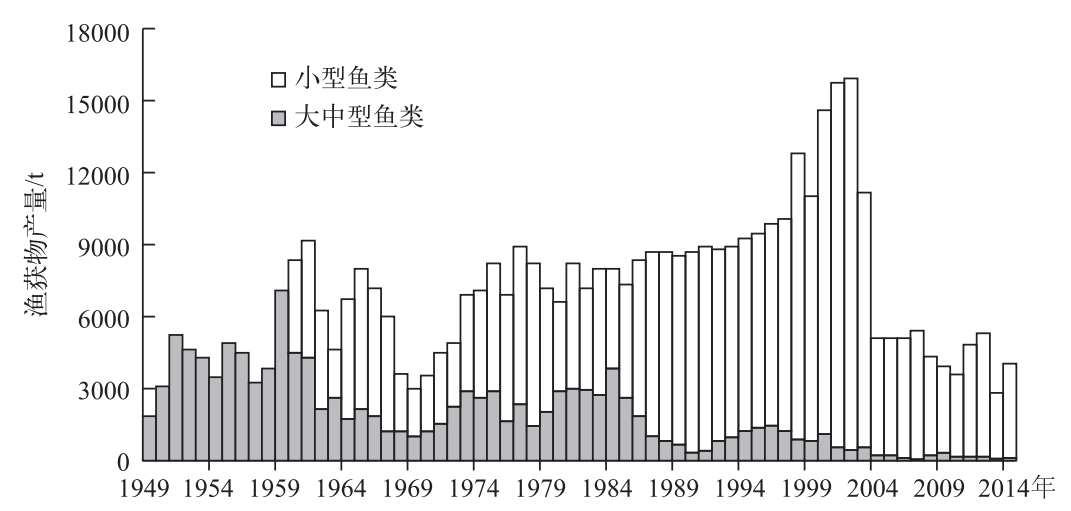

图 3 1949-2014 年呼伦湖自然渔业产量变动趋势

Fig. 3 Changes of fish catches from 1949 to 2014 in Lake Hulun

表 3 呼伦湖不同年代的渔获物组成比例 (年均值)

Tab. 3 Composition of fish catches in different years in Lake Hulun (annual means)

\begin{tabular}{lcccc}
\hline & $1970-1979$ 年 & $1980-1989$ 年 & $1990-1999$ 年 & $2000-2014$ 年 \\
\hline 渔获物总产量/t & 6618.3 & 7889.9 & 9116.6 & 5267.8 \\
均产量 $/\left(\mathrm{kg} / \mathrm{hm}^{2}\right)$ & 28.2 & 33.7 & 38.9 & 22.5 \\
贝氏䋜 & $68.1 \%$ & $71.0 \%$ & $88.9 \%$ & $95.4 \%$ \\
鲤 & $13.8 \%$ & $14.9 \%$ & $4.2 \%$ & $2.6 \%$ \\
鲌类 & $11.2 \%$ & $9.9 \%$ & $3.8 \%$ & $1.6 \%$ \\
银鲫 & $4.7 \%$ & $1.1 \%$ & $0.2 \%$ & $0.3 \%$ \\
瓦氏雅罗鱼 & 0 & $0.3 \%$ & $0.5 \%$ & $0.2 \%$ \\
鲇 & $2.1 \%$ & $2.3 \%$ & $2.3 \%$ & 0 \\
大中型鱼类 & $31.9 \%$ & $28.7 \%$ & $10.5 \%$ & $4.5 \%$ \\
小型鱼类 & $68.1 \%$ & $71.3 \%$ & $89.5 \%$ & $95.5 \%$ \\
\hline
\end{tabular}

\section{3 讨论}

\section{1 种类组成变化}

2014-2015 年本研究在呼伦湖区域共捕获鱼类 6 科 21 种, 而黑龙江水产研究所和内蒙古自治区渔业 区划办公室在 1973 年和 1981-1982 年的调查中合计采集到鱼类 30 种 ${ }^{[4]} .1990 \mathrm{~s}$ 呼伦湖渔业公司组织多次 鱼类资源调查,并根据以往文献记载,整理记录出呼伦湖鱼类种类共有 33 种 ${ }^{[14]}$.

与前几次调查结果相比, 呼伦湖鱼类的物种数量下降, 鱼类种类组成发生明显变化. 首先, 一些珍稀的 洄游性鱼类减少或消失, 如细鳞鮏 (Brachymystax lenok) 在本次调查中未采集到, 而哲罗鲑、江鳕的数量也极 少, 且可能为贝尔湖洄游至呼伦湖越冬的种群. 这些珍稀鱼类种类的下降与呼伦湖近年来河道堵塞、水位 下降以及捕捞强度加大密切相关 ${ }^{[2]}$. 其次, 近年来呼伦湖的鱼类增殖放流工作减少, 大银鱼、草鱼、团头鲂和 细鳞鱽等移人种, 因无资源补充而消失 ${ }^{[9]}$. 另外, 渔业资源的过度捕捞, 也导致一些具有地域性经济价值的 鱼类, 如花鳃和犬首鮈等的资源量大幅下降, 进而在此次调查中均未采集到, 虽然与调查频度和广度有关, 但说明其种群数量上呈现减少、衰退的趋势.

呼伦湖鱼类种类组成分布也与湖泊不同区域间的环境特征差异相关. 例如东部湖岸平缓,部分浅水区 域为鱼类优良的产卵场所, 而从东部注人呼伦湖的乌尔逊河则贯通了贝尔湖、乌兰泡和呼伦湖, 有利于鱼类 的洄游、迁移和繁殖, 这些因素均一定程度上增加了东部湖区的鱼类种类数量 ${ }^{[4]}$. 此外, 乌尔逊河也带来丰 富的营养物质, 附近水域中藻类等食物饵料充足 ${ }^{[5]}$, 浮游食性鱼类贝氏粲的比重也相对较高. 但东部湖区 
的生物多样性指数 $H^{\prime}$ 和 $J^{\prime}$ 却低于西部湖区, 这主要与西部湖区水体较深, 底栖动物生物量相对较高 ${ }^{[5]}$, 由此 导致鲤、银鲫等中下层大型鱼类数量较多相关 (表 2). 因此, 不同湖区鱼类的种类和群落组成差异一定程度 上反映出鱼类群落结构与湖泊环境特征相适应的特点.

\section{2 优势种组成及鱼类小型化趋势}

本次调查显示, 呼伦湖的优势种鱼类以贝氏粲这种经济价值不高且体型较小的种类为主, 所获渔获物 的平均个体质量仅为 $14.0 \mathrm{~g}$; 而贝氏粲在全湖区域内的尾数比及质量比分别为 $98.1 \%$ 和 $82.5 \%$, 其数量和生 物量均占绝对优势. 根据历史渔业资料分析, 1970s、1980s 呼伦湖中鲤、红鳍原鲌、银鲫、鲇等大中型经济鱼 类的生物量比例约占 30\% (表 3), 而 2000-2014 年间,大中型鱼类比例下降至 4. 5\%. 此外,优质鱼类的个 体也呈现小型化趋势, 1981 年呼伦湖鲤 $350 \sim 750 \mathrm{~g}$ 个体占其总数的 $78.8 \%{ }^{[4]}$, 而本次调查中采集到的鲤个 体的平均体重仅为 $337 \mathrm{~g}$. 由此可见, 呼伦湖鱼类主要优势种由大中型鱼类逐渐衰退到小型鱼类, 渔业资源 质量呈下滑趋势.

与之相应, 由于鱼类种类数下降和优势种小型化趋势加剧, 呼伦湖鱼类群落的多样性指数 $H^{\prime}{ }_{\mathrm{w}}$ 在各湖区 均表现偏低 $(0.58 \sim 0.82)$, 低于 Magurran ${ }^{[15]}$ 提出的多样性指数的一般范围 $(1.5 \sim 3.5)$. 目前国内湖泊普遍 出现优质高营养层次鱼类资源相继衰退, 而低营养层次的小型中上层鱼类资源逐渐增加的趋势 ${ }^{[16]}$. 与其中 一些出现鱼类小型化趋势的大型湖泊相比, 呼伦湖鱼类群落的多样性指数 $H^{\prime}{ }_{\mathrm{W}}(0.71)$ 高于太湖 $(0.46)^{[17]}$, 但低于博斯腾湖 (1.14 $)^{[18]}$. 多样性指数的差异可能与各湖泊优势种鱼类的大小相关, 其中 IRI 值前 5 位的 鱼类中, 太湖仅鳙为大中型鱼类, 而呼伦湖仅贝氏粲和瓦氏雅罗鱼为小型鱼类, 博斯腾湖仅池沼公鱼 $(H y-$ pomesus olidus) 为小型鱼类,优势种中大型鱼类比重的增加有利于生物多样性的提高.

在鱼类生物多样性研究中, Margalef、Shannon-Wiener 和 Pielou 等多样性指数通常以渔获物数量为计算 基础 ${ }^{[19]}$, 但 $\mathrm{Wilhm}^{[20]}$ 的研究表明, 当群体中个体差异较大时, 用生物量代替数量来表示生物多样性更能接 近种类间能量的分布. 本研究中呼伦湖鱼类群落基于个体数量的多样性指数 $H^{\prime}{ }_{\mathrm{N}}$ 明显低于基于生物量的多 样性指数 $H^{\prime}{ }^{\prime}$, 其他一些湖泊中的研究也存在一致的结论 ${ }^{[17]}$, 而造成这种差异的主要原因是呼伦湖鱼类群 落中小型鱼类占据了绝对优势, 以贝氏粲为代表的这种状况典型地反映了呼伦湖鱼类 “优势种单一化” 和 “小型化”的发展方向.

\section{3 渔业资源衰退的原因分析}

捕捞是生物多样性下降和渔业资源衰退的主要影响因素。呼伦湖渔业生产分为冰下捕捞和明水期捕捞 2 个生产期,渔具包括冰下大拉网、明水大拉网、白鱼网、覍网、挂网、虾网等 ${ }^{[14]}$, 各渔具网目不一 $(2 \sim 8 \mathrm{~cm})$, 基本 将大小鱼类全部捕获, 可见呼伦湖目前的捕捞工具对鱼类规格几乎没有选择性,整体捕捞强度过大对鱼类 资源组成产生较大影响. 通常情况下,大个体的鱼类受捕捞的影响明显大于小个体的鱼类,而贝氏粲等小型 鱼类较之大中型鱼类具有较强的补偿调节能力. Pauly 等 ${ }^{[21]}$ 也曾提出, 在捕捞的影响下, 高营养级的捕食者 (一般为个体较大、生命周期较长的种类) 持续减少, 并导致渔获物的组成向个体较小、营养层次较低、经济 价值不高的种类转变. 而这种影响又通过一些生态学过程进一步放大, 例如大中型肉食性鱼类种群的衰退 降低了其对小型鱼类种群的捕食与调控作用, 最终对群落结构产生影响. 呼伦湖的渔获物总产量也与捕捞 强度密切相关, 例如 1973 年渔业生产实现机械化后, 捕捞产量开始呈现逐年增长趋势; 而 2003 年为了降低 呼伦湖捕捞强度,冰下大拉网数量从 17 合减至 13 合, 2004 年又减至 7 合,捕捞产量也随之明显下降 (图 3).

其次, 湖泊水质与生物饵料资源变化也是影响鱼类群落组成的因素之一. 鱼类为湖泊生态系统食物链 结构的顶级消费者, 湖泊渔业与其营养物质水平、生物群落结构等密切相关并相互影响 ${ }^{[22]}$. 呼伦湖自 $1980 \mathrm{~s}$ 末就已进人富营养化状态, 其营养物质主要来自草原面源污染 ${ }^{[1]}$, 近年来随着营养盐的不断累积, 呼伦湖水 体的总氮、总磷浓度分别从 1988 年的 1.98 和 $0.13 \mathrm{mg} / \mathrm{L}$ 上升至 2009 年的 4.57 和 $0.37 \mathrm{mg} / \mathrm{L}^{[1,23]}$. 草原型 污染的特殊性表现为水体营养盐丰富, 通常会造成藻类等浮游植物的迅速增长和湖泊初级生产力的提高, 从而导致鱼类群落的生物㙁料基础发生改变 ${ }^{[17]}$. 例如, 呼伦湖浮游植物的生物量从 1988 年的 $8.07 \mathrm{mg} / \mathrm{L}$ 上 升至 2009 年的 $12.60 \mathrm{mg} / \mathrm{L}$, 增长 $56 \%{ }^{[1,23]}$. 而贝氏粲的主要食物为藻类等浮游生物, 因此呼伦湖的水体富 营养化间接为贝氏粲提供了丰富的食物饵料, 有利于其种群的迅速增长. 与之相对, 水质下降及富营养化加 剧也会带来严重的生态后果, 如氨氮浓度过高、藻类毒素的毒害作用、溶解氧降低等, 影响鱼类的繁殖与生 
长, 造成种类数减少及多样性下降 ${ }^{[24]}$.

另外,气候水文条件的改变也能引起鱼类资源的变动. 例如气候暖干化、水位下降、人湖径流补水量减 少等均可能对鱼类种群数量及分布产生重要影响 ${ }^{[2,17]}$. 近年来, 呼伦湖地区气候变化呈现出气温升高、降水 减少、蒸发量增大的暖干化趋势, 这些因子的综合作用, 导致湖水水域面积萎缩、水位大幅度下降 ${ }^{[2]}$. 其中自 1999 年以来, 呼伦湖水位已持续下降了 $4.99 \mathrm{~m}$, 至 2012 年达到最低水平 (水位 $539.8 \mathrm{~m}$ ). 水位下降一方面 导致湖泊面积及蓄水量迅速减少, 尤其是冬季结冰后, 冰下水深仅 $1 \sim 2 \mathrm{~m}$, 鱼类因缺氧大量死亡; 另一方面 水位下降造成沿湖岸边分布的鱼类产卵场干涸,鱼类的产卵繁殖受到显著影响 ${ }^{[14]}$.

综上, 呼伦湖鱼类群落生物多样性降低及鱼类小型化趋势加剧, 很大程度上应该是捕捞因素和自然环 境因素共同作用的结果. 针对呼伦湖渔业发展存在的问题, 如何控制渔业资源衰退趋势, 并在考虑保护湖 泊环境的前提下进行渔业资源结构调整优化, 是目前迫切需要解决的问题. 因此,在本研究的基础上,后期 需进一步在鱼类资源保护、增殖放流、捕捞强度控制及相关部门企业的管理机制改革等方面开展研究, 提出 和制定一系列渔业资源小型化的控制对策, 完成由传统的渔业管理向基于生态系统的管理模式的转变, 以 实现呼伦湖渔业的有序管理和可持续发展.

\section{4 参考文献}

[ 1 ] 金相灿. 中国湖泊环境. 北京: 海洋出版社, 1995: 457-495.

[2] 赵慧颖, 乌力吉, 郝文俊. 气候变化对呼伦湖湿地及其周边地区生态环境演变的影响. 生态学报, 2008, 38(3): 1064-1071.

[ 3 ] 白美兰, 郝润全, 沈建国. 近 46a 气候变化对呼伦湖区域生态环境的影响. 中国沙漠, 2008, 28(1) : 101-107.

[ 4 ] 严志德. 达㐘湖-莫力庙水库渔业资源调查论文集. 呼和浩特: 内蒙古人民出版社, 1985: 1-127.

[ 5 ] 徐占江. 呼伦湖志. 长春: 吉林文史出版社, 1989: 77-277.

[ 6 ] 李宝林, 赵贵民, 张路增等. 呼伦湖移植大银鱼初报. 淡水渔业, 1999, 29(12) : 23-24.

[ 7 ] 李树国, 张全诚, 高庆全等. 呼伦湖蒙古油粲繁殖生物学的研究. 淡水渔业, 2008, 38(5): 51-54.

[ 8 ] 李 华, 夏春丽, 李树国等. 内蒙古呼伦湖红鳍鲌的营养成分分析及营养评价. 营养学报, 2009, 31(3): 285-288.

[ 9 ] 缪丽梅, 张笑晨, 张 利等. 呼伦湖渔业资源调查评估及生态修复技术. 内蒙古农业大学学报: 自然科学版, $2014,35(4): 1-9$.

[10］陈宜瑜. 中国动物志・硬骨鱼纲 - 鲤形目 (中卷). 北京: 科学出版社, 1998: 1-531.

[11] 解玉浩. 东北地区淡水鱼类. 沈阳: 辽宁科学技术出版社, 2007: 1-483.

[12] Krebs CJ. Ecological methodology. New York: Harper Collins Publishers, 1989: 328-368.

[13] Pinkas L, Oliphant MS, Iverson ILK. Food habits of albacore, bluefin tuna, and bonito in California waters. California Department of Fish and Game Fish Bulletin, 1971, 152: 1-105.

[14] 张志波, 姜风元. 呼伦湖志 (续志一). 海拉尔: 内蒙古文化出版社, 1998: 24-26.

[15] Magurran AE. Ecological diversity and its measurement. New Jersey: Princeton University Press, 1988: 7-45.

[16] 刘其根, 沈建忠, 陈马康等. 天然经济鱼类小型化问题的研究进展. 上海水产大学学报, 2005, 14 (1) : 79-83.

[17] 毛志刚, 谷孝鸿, 曾庆飞等.太湖鱼类群落结构及多样性研究. 生态学杂志, 2011, 30(12) : 2836-2842.

[18] 陈 朋, 马燕武, 谢春刚等. 博斯腾湖鱼类群落结构的初步研究. 淡水渔业, 2014, 44(2)：36-42.

[19］童春富. 长江河口潮间带盐沼植被分布区及邻近光滩鱼类组成特征. 生态学报, 2012, 32(20)：6501-6510.

[20] Wilhm JL. Use of biomass units in Shannon's formula. Ecology, 1968, 49: 153-156.

[21] Pauly D, Christensen V, Dalsgaard J et al. Fishing down marine food webs. Science, 1998, 279(6) : 860-863.

[22] 孙 刚, 盛连喜, 冯 江等. 中国湖泊渔业与富营养化的关系. 东北师大学报: 自然科学版, 1999, (1) : 74-78.

[23] 王 俊, 冯伟业, 张 利等. 呼伦湖水质和生物资源量监测及评价. 水生态学杂志, 2011, 32(5): 64-68.

[24] Tammi J, Lappalainen A, Mannio J et al. Effects of eutrophication onfish and fisheries in Finnish lakes: a survey based on random sampling. Fisheries Management and Ecology, 1999, 6: 173-186. 